\title{
Correlation between ultrasound and histopathological findings of products of uterine evacuation in cases admitted after medical abortion
}

\section{Veena Vidyasagar*}

\author{
Department of Obstetrics \& Gynaecology, School of Medical Sciences and Research, Sharda University, Greater \\ Noida, UP, India
}

Received: 08 August 2015

Revised: 17 August 2015

Accepted: 23 August 2015

\section{*Correspondence:}

Dr. Veena Vidyasagar,

E-mail: vinav2002@yahoo.co.in

Copyright: $\odot$ the author(s), publisher and licensee Medip Academy. This is an open-access article distributed under the terms of the Creative Commons Attribution Non-Commercial License, which permits unrestricted non-commercial use, distribution, and reproduction in any medium, provided the original work is properly cited.

\begin{abstract}
Background: The present study was undertaken to evaluate correlation between ultrasound findings and histological diagnosis in cases which were taken up for uterine evacuation on the suspected diagnosis of retained products of conception (RPOC) following medical abortion.

Methods: A retrospective study was undertaken of cases admitted as RPOC/ failed medical abortion following selfmedication for inducing abortion, at Sharda Hospital, Greater Noida. The time period of the study was from 01 Jan 2012 to 31 Aug 2014. The inclusion criteria of cases were H/O intake of drugs for induction of abortion by selfmedication, evidence suggestive of RPOC/ failed medical abortion and cases that underwent uterine evacuation. Case documents of patients were studied and the available details noted down. The data were subjected for statistical analysis. Correlation between ultrasound and histopathological findings was evaluated.

Results: There were 243 inpatients, during the study period, which fulfilled the inclusion criteria. Ultrasound was performed in 172 cases. Histopathological examination of specimen was performed in 190 cases. Majority of these (123 - 64.74\%) specimen showed features consistent with products of conception. Evidence of products of conception was seen in $64.29 \%$ cases with ET 7-10 mm, in $74.07 \%$ cases with ET $11-15 \mathrm{~mm}$ and in $90.91 \%$ cases with ET $16-20$ $\mathrm{mm}$ on ultrasound.

Conclusions: A retrospective study of suspected cases of RPOC/ failed medical abortion following medical abortion was undertaken. Possibility of products of conception increased with ET increasing from 7 to $20 \mathrm{~mm}$. There was also evidence of increase in ET from 7 to $25 \mathrm{~mm}$ with increased duration of bleeding PV.
\end{abstract}

Keywords: Retained products of conception, Induction of abortion, Ultrasound, Histopathological examination, ET

\section{INTRODUCTION}

Medical treatment to induce abortion has been shown to be a reasonable alternative to surgical evacuation during the last few decades. It avoids surgical complications, is easy to follow by patients and is cost effective. ${ }^{1}$ Incomplete medical abortion may, however, increase the risk of infection and has been associated with persistent or recurrent bleeding per vaginum and pain. The risk of failure of medical treatment appears to be related to advanced gestational age, high body mass index, improper intake of drugs (self-medication) and multiparty. ${ }^{2,3}$

The diagnosis of failed medical abortion usually leads to surgical intervention. Reasons for early curettage usually have included retained POC, intractable pain, or massive bleeding. Late failures are generally noticed after the 2to 4-week follow-up visit and are defined as retained POC, commonly presenting with prolonged vaginal bleeding. Generally, bleeding after medical abortion lasts 
longer than after vacuum evacuation of an early gestation. If the patient is in good general condition, neither prolonged bleeding nor the presence of tissue in the uterus (as detected by ultrasound) is an unequivocal indication for surgical intervention. Surgical evacuation of the uterus may be carried out on the patient's request or if the bleeding is heavy or prolonged, causes anaemia, or in evidence of infection. In the latter case, antibiotic treatment should be initiated. ${ }^{4-6}$

Ultrasound is typically the first-line investigation in suspected cases of retained products of conception (RPOC). Variable amount of echogenic or heterogeneous material within the endometrial cavity, presence of vascularity within the echogenic material supports the diagnosis, and helps to differentiate it from intrauterine blood clot. RPOC can be suspected on ultrasound if the endometrial thickness is $>10 \mathrm{~mm}$ (15 mm according to some studies) following dilatation and curettage or spontaneous abortion ( $80 \%$ sensitive). There is marked overlap in the sonographic uterine appearance of asymptomatic and symptomatic women; the endometrial cavity is commonly irregular and thickened and may show prominent colour Doppler flow in women with an uneventful course, as well as those with histologically proven RPOC. ${ }^{7}$ Ultrasound interpretation often influences the choice to perform uterine evacuation in cases of suspected retained products of conception (RPOC) following induced abortion. The combination of a hyperechoic endometrial mass or solid component within the endometrium and abnormal (heavy or prolonged) bleeding or infection is a sensitive indicator of RPOC. In the absence of clinical symptoms, surgical intervention for these ultrasound findings is not indicated, as prevention of future morbidity is unproven. ${ }^{8-10}$ Many studies have concluded that most of the women regained normal menses without further surgical intervention following diagnosis of failed medical abortion, suggesting that remnants of trophoblastic tissue get spontaneously evacuated from the uterine cavity. ${ }^{4,10}$

There is no agreement about the value of submitting tissue for histological examination obtained at uterine curettage in suspected cases of RPOC. One philosophy is to investigate only those women in whom there is some uncertainty over the diagnosis pre-operatively, or when there is doubt about the diagnosis at the time of the operation. $^{11,12}$ The alternative view is that expressed in texts discussing legal aspects relating to clinical practice, suggesting that for all uterine evacuations a sample of tissue should be submitted for histological examination. $^{13,14}$ This opinion is clearly promoted as a protection to the obstetrician but it is not clear whether it is justified.

The objective of the present study was to determine whether there is any correlation between ultrasound findings and histopathological examination reports of the tissue removed at the time of uterine evacuation for failed medical abortion.

\section{METHODS}

A retrospective study was undertaken of cases admitted as retained products of conception/ failed medical abortion following self-medication for inducing abortion, at Sharda Hospital, Greater Noida. The time period of study was from 01 Jan 2012 to 31 Aug 2014. The inclusion criteria of cases for the purpose of study were $\mathrm{H} / \mathrm{O}$ intake of drugs for induction of abortion by selfmedication, evidence suggestive of retained products of conception/ failed medical abortion on clinical examination and/ or by ultrasound and cases that underwent uterine evacuation. Case documents of patients who satisfied the inclusion criteria were studied and the available details noted down. The details noted included patient's particulars, dates of admission/ evacuation/ discharge, duration of gestation at the time of intake of drugs for induction of abortion, time elapsed between intake of drugs and admission, complaints before admission and their duration, laboratory investigation reports, ultrasound findings, any specific treatment given, blood transfusion administered and any complications encountered. Reports of histopathological examination of specimen of uterine evacuation were noted from the records maintained by Histopathological section of Central Laboratory of Sharda Hospital, Greater Noida. The data were subjected for Statistical analysis. Correlation between ultrasound findings and histopathological diagnosis was studied.

\section{RESULTS}

There were 243 inpatients, during the study period, which were admitted as cases of retained products of conception/ failed medical abortion and fulfilled the inclusion criteria. Details of drugs taken for induction of abortion were not available from the case documents. The mean age of patients in the study was $27.71 \pm 4.57$ years. Distribution of patients according to age group is shown in Table 1 . The mean parity of patients was $2.4 \pm 1.21$. There were 10 nullipara and 3 patients were unmarried. The highest parity was 7. Distribution of patients according to parity is shown in Table 2. The average gap between the last delivery and last conception (which was terminated by medical abortion) was $3.57 \pm 2.46$ years. Mean gestation at which inpatients took medication for abortion was $7.68 \pm 0.5$ weeks. Distribution of patients according to period of gestation is shown in Table 3 .

Table 1: Distribution of patients according to age.

\begin{tabular}{|ll|}
\hline \hline Age group (years) & Number \\
\hline$<20$ & 2 \\
\hline $20-25$ & 56 \\
\hline $25-30$ & 103 \\
\hline $30-35$ & 51 \\
\hline$\geq 35$ & 1 \\
\hline Mean \pm SD & $27.71 \pm 4.57$ \\
\hline
\end{tabular}


Table 2: Distribution of patients according to parity.

\begin{tabular}{|ll|}
\hline Distribution of patients according to parity \\
\hline Parity & Number \\
\hline 0 & 10 \\
\hline 1 & 44 \\
\hline 2 & 85 \\
\hline 3 & 70 \\
\hline 4 & 23 \\
\hline 5 & 6 \\
\hline 6 & 3 \\
\hline 7 & 2 \\
\hline Mean \pm SD & $2.4 \pm 1.21$ \\
\hline
\end{tabular}

Table 3: Distribution of patients according to period of gestation when drugs for abortion were taken.

\begin{tabular}{|lc|}
\hline Period of gestation (wks) & Number \\
\hline$<5$ & 10 \\
\hline $5-6$ & 29 \\
\hline $6-7$ & 90 \\
\hline $7-8$ & 23 \\
\hline $8-9$ & 59 \\
\hline $9-10$ & 0 \\
\hline $10-11$ & 18 \\
\hline $11-12$ & 1 \\
\hline$\geq 12$ & 13 \\
\hline Mean \pm SD & $7.68 \pm 0.5$ weeks \\
\hline
\end{tabular}

Average number of days between intake of abortifacient and reporting for admission was $19.33 \pm 16.26$ days. 233(95.88\%) women in the study period reported with the main complaint of bleeding per vaginum. $10(4.12 \%)$ cases didn't have bleeding PV at the time of admission. They had pain lower abdomen and found to have USG features suggestive of retained products of conception. $12(4.94 \%)$ cases had mild to moderate fever. Average number of days of bleeding PV before admission was $14.03 \pm 14.44$. In $121(51.93 \%)$ cases bleeding per vaginum started the same day when the abortifacient was taken. In other cases, the average gap between the intake of abortifacient and onset of bleeding PV was $11.37 \pm$ 15.38 days.

Routine investigations like $\mathrm{CBC}, \mathrm{Rh} \& \mathrm{ABO}$ grouping, $\mathrm{HIV}$ and $\mathrm{HbsAg}$ were done in all cases. Average value of Haemoglobin of patients was $9.35 \pm 2.21 \mathrm{gms} \%$. There were 26 patients $(10.7 \%)$ whose $\mathrm{Hb}$ was $<6.5$ gms\%. 11 $(42.3 \%)$ of these cases received blood transfusions.

Ultrasound was performed in 172 cases. In other cases, USG was not done in view of clinical diagnosis of incomplete abortion and/ or patient presented with excessive bleeding $\mathrm{PV}$, which required immediate attention. Details of ultrasound features are shown in Table 4.
Table 4: Distribution of patients according to USG reports.

\begin{tabular}{|ll|}
\hline USG report & Number \\
\hline Intrauterine live gestation & 9 \\
\hline Missed abortion & 7 \\
\hline Irregular gestation sac & 4 \\
\hline $\begin{array}{l}\text { Features suggestive of } \\
\text { retained products of } \\
\text { conception }\end{array}$ & $152^{*}$ \\
\hline Total & 172 \\
\hline
\end{tabular}

*In 78 cases the thickness/ measurement of intrauterine contents was mentioned. In other 74 cases the details were not mentioned in the case documents. It was only documented that USG features are suggestive of retained products of conception.

Table 5: Distribution of cases according to histopathology report.

\begin{tabular}{|ll|}
\hline Histopathology report & Number \\
\hline Consistent with products of conception & 123 \\
\hline Infected products of conception & 9 \\
\hline Chorionic villi with endometrial glands & 1 \\
\hline $\begin{array}{l}\text { Features suggestive of hydropic } \\
\text { degeneration }\end{array}$ & 1 \\
\hline Decidua & 12 \\
\hline Infected decidua & 13 \\
\hline Decidua with endometrial glands & 8 \\
\hline Chronic endometritis & 6 \\
\hline Secretory endometrium & 7 \\
\hline Proliferative endometrium & 1 \\
\hline $\begin{array}{l}\text { Fragmented endometrial, endocervical } \\
\text { and/ or ectocervical glands }\end{array}$ & 9 \\
\hline Total & 190 \\
\hline
\end{tabular}

$152(88.37 \%)$ cases in which ultrasound was done, showed features suggestive of retained products of conception and $9(5.23 \%)$ cases showed intrauterine live gestation. The measurement of thickness of intrauterine contents was not mentioned in $74(48.68 \%$ ) cases in case documents. Ultrasound reports in which details of findings were mentioned were done by ultrasonologist at Radiology department of School of medical sciences and research, Sharda University, Greater Noida.

Histopathological examination of specimen was performed in 190 cases. Majority of these (123 - 64.74\%) specimen showed features consistent with products of conception, $9(4.74 \%)$ cases had features of infected products of conception, $12(6.32 \%)$ cases had features of decidua, $13(6.84 \%)$ had features of infected decidua and $8(4.2 \%)$ cases showed features of decidua with endometrium. There were $23(12.1 \%)$ specimen which did not show any feature related to pregnancy. The details 
of histopathological reports of specimen are shown in Table 5. Histopathological reports in relation to USG findings are shown in Table 6 . The sum of the number of specimen mentioned in the table doesn't match with the total number of specimen tested. This is due to the fact that not all of them had undergone ultrasound examination.

As per Table 6, most samples of evacuation showed features consistent with products of conception, their probability increasing from $7-10 \mathrm{~mm}$ group to $16-20 \mathrm{~mm}$ group. Relationship between USG findings and number of days of bleeding per vaginum before admission in cases showing evidence of products of conception was as follows: in cases where USG showed RPOC (without measurement of thickness of intrauterine contents) average number of days of bleeding PV was 15.32 , with ET between 7 and $10 \mathrm{~mm}$ it was 13.75 days, with ET between 11 and $15 \mathrm{~mm}$ it was 16.625 days, with ET between 16 and $20 \mathrm{~mm}$ it was 34.8 days, with ET between 21 and $25 \mathrm{~mm}$ it was 37.5 days and it was 7 days where ET exceeded $25 \mathrm{~mm}$. Thus, number of days of bleeding PV increased from lower to higher value of ET except when ET was $>25 \mathrm{~mm}$. In cases, where live intrauterine gestation was seen on USG, 3 cases did not have bleeding PV. In other cases, average duration of bleeding PV was 11.4 days.

Table 6: Histopathological reports in relation to USG findings.

\begin{tabular}{|c|c|c|c|c|c|c|c|}
\hline \multirow[t]{2}{*}{ USG findings } & \multicolumn{7}{|c|}{ Histopathological reports } \\
\hline & $\begin{array}{l}\text { Consistent } \\
\text { with POC }\end{array}$ & $\begin{array}{l}\text { Infected } \\
\text { POC }\end{array}$ & Decidua & $\begin{array}{l}\text { Infected } \\
\text { decidua }\end{array}$ & $\begin{array}{l}\text { Decidua with } \\
\text { endometrium }\end{array}$ & Endometrium & Endometritis \\
\hline $\mathrm{RPOC}^{+}$ & $42 *$ & 4 & 3 & 5 & 4 & 4 & 5 \\
\hline ET $\quad 7-10 \mathrm{~mm}$ & 8 & 1 & 1 & 1 & 1 & 2 & \\
\hline ET $11-15 \mathrm{~mm}$ & 18 & 2 & 1 & 1 & $2 * *$ & 2 & 1 \\
\hline ET $16-20 \mathrm{~mm}$ & 10 & & & & & 1 & \\
\hline ET $21-25 \mathrm{~mm}$ & 2 & & & 1 & & & \\
\hline $\mathrm{ET}>25 \mathrm{~mm}$ & 2 & & & & & 1 & \\
\hline Live IU gestation & 8 & & & & & & \\
\hline Irregular gestation sac & 3 & & & & 2 & & \\
\hline Missed abortion & 2 & & & 1 & & & \\
\hline
\end{tabular}

- * *ne case showed features suggestive of hydropic degeneration

- $\quad * *$ One case showed focal Arias Stellar reaction

- $\quad{ }^{+}$Measurement of IU contents not mentioned in USG findings

\section{DISCUSSION}

The diagnosis of a failed medical abortion usually leads to surgical intervention. Medical termination of pregnancy (TOP) is considered successful whenever complete abortion occurs without the need for surgical intervention, and no serious side effects occur. The need for surgical intervention due to sonographic findings after medical TOP is not clearly defined in the present literature.

A thickened endometrium has been used as a sign of RPOC. Endometrial thickness is determined by measuring the width of the endometrium in the anteriorposterior dimension. Relatively arbitrary cut-off values of 8 to $25 \mathrm{~mm}$ have been defined in the literature. ${ }^{15}$ However; there is no good evidence that any cut-off is clinically useful. ${ }^{6}$ The mean endometrial thickness in the study by El-Baradie SMY et al. ${ }^{16}$ was $11.2 \pm 3.9 \mathrm{~mm}$ in the complete abortion group and $14.6 \pm 6.1 \mathrm{~mm}$ in the incomplete abortion group, a statistically significant difference $(\mathrm{P}=0.003)$.

Rorbye et al. ${ }^{17}$ concluded that the clinical presentation is more accurate than sonographic measurement of the endometrial thickness for defining failure of medical TOP, 14-30 days after treatment. Extended follow-up, in this study, was linked to higher rate of surgical intervention. Cowett et al. ${ }^{6}$ found that the range of endometrial thickness after medical TOP was wide, with a significant overlap between the groups and they recommended that clinicians intervene not only when a persistent gestational sac is seen on TVS, but also on the basis of compelling clinical indications. Fiala et al. ${ }^{4}$ suggested that the sonographic findings on follow-up were sometimes difficult to interpret and may lead to unnecessary surgical intervention, and found that serum $\beta \mathrm{HCG}$ was more effective in the follow-up after medical abortion. 
There is no consensus regarding the criteria for follow-up and success, and the indications for surgical intervention are equivocal. ${ }^{18}$ The cut-off values of endometrial thickness have not been prospectively validated. ${ }^{17}$ Reasons for curettage usually have included retained intrauterine pregnancy, or massive bleeding. It is expected that the intrauterine debris presented after medical abortion will be expelled in the next menstruation. ${ }^{19} \mathrm{~A}$ wide variation in endometrial thickness is seen after expulsion of the gestational sac, and that the thickness generally decreases with time. Many authors suggested that D\&E for failed medical abortion should be avoided unless clinical symptoms or signs necessitate this procedure. ${ }^{4}$

Measurement of endometrial width after medical TOP is beneficial in segregating patient to low or high risk for surgical treatment of retained product of conception [POC]. Using a cut-off of $11 \mathrm{~mm}$ during the follow-up visit after medical TOP, $18 \%$ of the patients may need dilatation and curettage to complete the pregnancy termination, and if it is $14 \mathrm{~mm}$, half of them may need surgical intervention. There is no difference between 11 and $14 \mathrm{~mm}$ regarding the risk of surgical intervention after medical TOP. ${ }^{21}$ An endometrial mass is the most sensitive finding for RPOCs, as per the study by Blumenfeld $\mathrm{F}$ et al. ${ }^{20}$ If no mass or endometrial fluid is seen and the endometrial thickness is less than $10 \mathrm{~mm}$, RPOCs are extremely unlikely. However, in our study, in cases where ET was between 7 and $10 \mathrm{~mm}$, majority of patients' specimen (64.29\%) showed evidence of products of conception. In our study, histopathological evidence of products of conception was maximum in 16$20 \mathrm{~mm}$ ET group $(90.91 \%)$ followed by ET $11-15 \mathrm{~mm}$ group $(74.07 \%)$. Number of patients with ET $>20 \mathrm{~mm}$ whose specimen were subjected for histopathological examination was small (6 cases). Evidence of products of conception was seen in $66.67 \%$ in them.

As per the study by El-Baradie SMY et al. ${ }^{16}$ quantitative assay of serum $\beta$-hCG and ultrasound measurement of endometrial thickness are clinically useful measures for predicting late failure of medical abortion, but should be used as supplements to clinical assessments. A welldefined endometrial line, with a maximum thickness of $15 \mathrm{~mm}$, combined with absence of vaginal bleeding, are considered as complete abortion according to guidelines from the Royal College of Obstetricians and Gynecologists for spontaneous abortions. ${ }^{21}$ However, these cut-off values have never been prospectively validated. $^{23}$

Neither [beta]-hCG nor endometrial thickness can be used clinically as diagnostic tests in predicting late failure after medical abortion as per the study by Rorbye et al. ${ }^{17}$

Routine histopathological examination of tissue obtained at abortion procedures is not recommended as per RCOG guidelines. ${ }^{23}$ Guidelines also recommend that ultrasound examination should not be used routinely to screen women for incomplete abortion.
While ultrasound examination will reliably exclude continuing pregnancy, its routine use in women suspected of incomplete abortion can be misleading. Ultrasound appearances and measurements of endometrial thickness correlate poorly both with symptoms suggestive of retained products of conception and with later histological examination as per RCOG publication. The decision to undertake uterine evacuation should be based upon the presence of signs and symptoms.

It is important to ensure that obstetricians who perform termination of pregnancy and evacuation for failed pregnancy and incomplete miscarriage should receive careful training to ensure complete evacuation rather than rely on routine histological examination of products of conception. ${ }^{17}$ Histological examination would seem logical in women with an uncertain pre-operative diagnosis, when less tissue than expected has been obtained, when trophoblastic tissue is not readily identified at surgery, or if routine inspection during the operation suggests that there may be unexpected pathology. The care of the woman thereafter should take into account not only the histological findings but also her initial history and clinical examination and her subsequent symptoms.

Dr Matt A. Morgan and Radswiki et al. have mentioned in Radiopedia.org. that, there is great variability among studies in terms of diagnostic and patient management criteria No studies have blinded managing clinicians to the ultrasound results, and ultrasound interpretation often influences the choice to perform uterine evacuation. Thus, although histologic findings can often be correlated with imaging results in symptomatic patients with abnormal ultrasound scans; there is less information about RPOC in symptomatic women with normal ultrasound scans. Likewise, the clinical outcome of expectant management of symptomatic women with abnormal ultrasound findings cannot be determined since these patients often undergo surgical intervention. The consequences of overlooking failed uterine evacuation are mostly limited, because the risk of serious morbidity associated with retained tissue is minimal and because failures ultimately will be revealed clinically.

It should be emphasized that choosing a low endometrial thickness cut-off point for clinical intervention would lead to unnecessary surgical treatment for a significant number of patients. Increasing the cut-off would decrease the false positive rate and improve the specificity of the test measurement. In the study by El-Baradie et al, ${ }^{16}$ when the cut-off point for endometrial thickness was 12 $\mathrm{mm}$, the positive likelihood ratio was 85.57 and the negative likelihood ratio was 3.36. Markovitch et al found no correlation between the patients' reports of symptoms and the sonographic findings, and they found that an intrauterine echogenic mass with or without Doppler flow signals may not infrequently be detected two weeks after medical termination of pregnancy. They concluded that this finding could indicate remnants of 
trophoblastic tissue that will pass spontaneously without the need for dilatation and curettage. ${ }^{10}$

The major arguments for encouraging histological examination of tissue removed at termination of pregnancy or surgical evacuation of the uterus are to confirm the pre-operative diagnosis, identify unexpected pathology and ensure that a pregnancy does not remain undisturbed. Routine submission of tissue collected at the time of surgery does not reliably confirm or correct the pre-operative diagnosis; neither ensures that the uterus is empty following the surgery nor that a pregnancy has not been effectively surgically terminated.

In the study by Alsibiani SA 25, histopathologic examination results were as follows: RPOC, 537 (96.2\%) patients; no RPOC, 17 (3\%) patients; complete molar pregnancy, $1(0.2 \%)$ patient; partial molar pregnancy, 1 $(0.2 \%)$ patient; and decidual tissue without chorionic villi (Arias-Stella reaction), $2(0.4 \%)$ patients. The study by Alsibiani SA et al recommended that histopathological examination be performed in select instances: when the diagnosis is uncertain, when fewer tissues have been obtained during surgery, when unexpected pathology was seen, when ultrasound suggests a molar pregnancy, or when patients are considered at high risk for trophoblastic disease. In our study, $133(70 \%)$ specimen showed features consistent with products of conception, 33 $(17.37 \%)$ specimen showed features consistent with decidua with/ without endometrium and $23(12.11 \%)$ specimen did not show evidence of either products of conception or decidua. There was $1(0.53 \%)$ specimen out of 190 , which showed features suggestive of hydropic degeneration and one specimen showed Arias Stellar reaction. In the study by Peterson SG et al, chorionic villi were not identified in four out of twelve women who underwent surgery for suspected RPOC. ${ }^{26}$ In our study, chorionic villi were not identified in 56 out of 190 specimens (29.47\%) who were subjected for histopathological examination.

Although most studies have reported an average duration of bleeding after medical abortion of approximately seven days, bleeding may last for as long as 21 days. $^{27-29}$ In our study, average number of days of bleeding PV was $14.03 \pm 14.44$. This is much higher than documented in other studies. In the event of persistent bleeding, surgical intervention should be considered only after careful evaluation of the patient.

The relationship between USG findings, histopathologic reports and number of days of bleeding per vaginum in our study were as follows: in cases where USG showed RPOC (without measurement of thickness of intrauterine contents) with HP report consistent with products of conception, average number of days of bleeding PV was 15.32, with ET between 7 and $10 \mathrm{~mm}$ it was 13.75 days, with ET between 11 and $15 \mathrm{~mm}$ it was 16.625 days, with ET between 16 and $20 \mathrm{~mm}$ it was 34.8 days, with ET between 21 and $25 \mathrm{~mm}$ it was 37.5 days and it was 7 days where ET exceeded $25 \mathrm{~mm}$. Thus, number of days of bleeding per vaginum showed proportionate increase with the increase in dimension of ET from 7 to $25 \mathrm{~mm}$. There were only 3 cases wherein ET measurement was beyond $25 \mathrm{~mm}$ and these cases reported with mean duration of bleeding per vaginum of 7 days.

\section{CONCLUSIONS}

A retrospective study of cases admitted as retained products of conception following self-medication for abortion was done. Patients who had undergone uterine evacuation were included in the study. Histopathological study was done in $78.19 \%$ cases. Most of the specimen of products of evacuation (70.53\%) showed features suggestive of products of conception. Evidence of products of conception on histopathological examination increased with increase in ET from 7 to $20 \mathrm{~mm}$ on ultrasound. There was proportionate increase in the number of days of bleeding per vaginum with increase in endometrial thickness between 7 and $25 \mathrm{~mm}$. Though, most of the studies quoted do not recommend routine histopathological examination of products of evacuation in suspected cases of RPOC, it is advisable to be done in view of its medico legal implications.

\section{ACKNOWLEDGEMENT}

I thank Medical Superintendent of Sharda Hospital, Greater Noida for giving me permission to go through the case files of patients. I also acknowledge cooperation extended by staff of Medical records department for providing me old case files for study.

\section{Funding: No funding sources \\ Conflict of interest: None declared \\ Ethical approval: Approved}

\section{REFERENCES}

1. Jurkovic D, Ross JA, Nicolaides KH. Expectant management of missed abortion. $\mathrm{Br} \mathrm{J}$ Obstet Gynecol. 1998;105:670-1.

2. Grimes DA, Bernstein L, Lacarra M, Shoupe D, Mishell DR Jr. Predictors of failed attempted abortion with the antiprogestin mifepristone (RU 486). Am J Obstet Gynecol. 1990;162:910-5.

3. Bartley J, Tong S, Everington D, Baird DT. Parity is a major determinant of success rate in medical abortion: a retrospective analysis of 3161 consecutive cases of early medical abortion treated with reduced doses of mifepristone and vaginal gemeprost. Contraception. 2000;62:297-303.

4. Fiala C, Safar P, Bygdeman M and GemzellDanielsson K. Verifying the effectiveness of medical abortion ultrasound versus hCG testing. EurJ Obstet Gynecol Reprod Biol. 2003;109:190-5.

5. Acharya G, Haugen M, Bråthen A, Nilsen I, Maltau JM. Role of routine ultrasonography in monitoring the outcome of medical abortion in a clinical setting. 
Acta. Obstetrica et Gynecologica Scandinavica. 2004;83:390-4.

6. Cowett AA, Cohen LS, Lichtenberg ES, Stika CS. Ultrasound evaluation of the endometrium after medical termination of pregnancy. Obstet Gynecol, 2004;103:871-5.

7. Machtinger R, Seidman DS, Goldenber M, Stockheim D, Schiff E and Shulman A. Fertility and Sterility. 2005;84:1536-8.

8. Luise C, Jermy K, May C, Costello G, Collins WP and Bourne T. Outcome of expectant management of spontaneous first trimester miscarriage observational study. BMJ. 2002;324:873-5.

9. Condous $\mathrm{G}$, Okaro $\mathrm{E}$ and Bourne $\mathrm{T}$. The conservative management of early pregnancy complications a review of the literature. Ultrasound Obstet. Gynecol. 2003;22:420-30.

10. Markovitch O, Tepper R., Klein Z, Fishman A and Aviram R. Sonographic appearance of the uterine cavity following administration of mifepristone and misoprostol for termination of pregnancy. J. Clin. Ultrasound. 2006;34:278-82.

11. Gal A, Stenning H. Pitfalls in the diagnosis of ectopic pregnancy. Med J Aust. 1985;143:411-412.

12. Jauniaux E, Kadri R, Hustin J. Partial mole and triploidy: screening patients with first-trimester spontaneous abortion. Obstet Gynecol. 1996;88:6169.

13. Nielsen S, Hahlin M. Expectant management of firsttrimester spontaneous abortion. Lancet. 1995;345:84.

14. Lee CY, Madrazo B, Drukker BH. Ultrasonic evaluation of the postpartum uterus in the management of postpartum bleeding. Obstet Gynecol. 1981;58:227-32.

15. Nielsen S, Hahlin M. Expectant management of firsttrimester spontaneous abortion. Lancet. 1995;345:84.

16. El-Baradie SMY, El-Said MH, Ragab WS, Elssery KM, Mahmoud M. Endometrial Thickness and Serum $\beta-h C G$ as predictors of the effectiveness of Oral Misoprostol in Early Pregnancy Failure. J Obstet Gynaecol Can. 2008;30(10):877-881.

17. Rorbye C, Norgaard M. and Nilas L. Prediction of late failure after medical abortion from serial betahCG and ultrasonography. Hum. Reprod. 2004;19:85-8.

18. Rorbye C, Norgaard, Vestermark V. and Nilas L. Medical abortion defining success and categorizing failures. Contraception. 2003;68:247-51.
19. Machtinger R, Seidman DS, Goldenberg M, Stockheim D, Schiff E. and Shulman A. Fertility and Sterility 2005;84:1536-8.

20. Blumenfeld F., Abdallah W, Kaplan D. and Nevo O. Endometrial Thickness - A Practical Prospective marker for the Risk of Surgical Intervention after RU486 Induced Abortion. Clinical Medicine: Reproductive Health. 2008:225-30

21. RCR/RCOG Working Party. Early pregnancy assessment. London: RCOG Press;1996.

22. Condous G, Okaro E. and Bourne T. The conservative management of early pregnancy complications a review of the literature. Ultrasound Obstet. Gynecol. 2003;22:420-30.

23. The care of Women requesting induced abortion, Evidence-based Clinical guidelines Number 7; November 2011 RCOG publication

24. Cooke I, Manek S and MacKenzie IZ. Should tissue from pregnancy termination and uterine evacuation routinely be examined histologically? BJOG. 2000; 107(6):727-730.

25. Alsibiani SA. Value of Histopathologic Examination of Uterine Products after First-Trimester Miscarriage. BioMed Research International, vol. 2014, Article ID 863482, 5 pages, 2014. Doi:10.1155/2014/863482

26. Petersen SG, Perkins AR, Gibbons KS, Bertolone JI and Mahomed K. The medical management of missed miscarriage: outcomes from a prospective, single-centre. Australian cohort. Med J Aust. 2013; 199 (5):341-346

27. Schaff EA, Fielding SL, Eisinger SH, Stadalius LS, Fuller L. Low-dose mifepristone followed by vaginal misoprostol at 48 hours for abortion up to 63 days. Contraception. 2000;61:41-6.

28. Mishell DR, Jain JK, Byrne JD, Lacarra MD. A medical method of early pregnancy termination using tamoxifen and misoprostol. Contraception. 1998;58:1-6.

29. Jain JK, Meckstroth KR, Mishell DR Jr. Early pregnancy termination with intravaginally administered sodium chloride solution-moistened misoprostol tablets: historical comparison with mifepristone and oral misoprostol. Am J Obstet Gynecol.1999;181:1386-91.

Cite this article as: Vidyasagar V. Correlation between ultrasound and histopathological findings of products of uterine evacuation in cases admitted after medical abortion. Int J Reprod Contracept Obstet Gynecol 2015;4:1446-52. 